\title{
Hydrodynamic Model for Operational Forecasting in Coastal Waters of Ghana
}

\author{
Felix Uba, Eric Osei Essandoh, Emmanuel K. Nyantakyi, Prosper Anumah \\ University of Energy and Natural Resources, Sunyani, Ghana \\ Email: felix.uba@uenr.edu.gh
}

How to cite this paper: Uba, F., Essandoh, E.O., Nyantakyi, E.K. and Anumah, P. (2020) Hydrodynamic Model for Operational Forecasting in Coastal Waters of Ghana. Open Journal of Modelling and Simulation, 8, 48-59.

https://doi.org/10.4236/ojmsi.2020.82004

Received: April 3, 2020

Accepted: April 24, 2020

Published: April 27, 2020

Copyright $\odot 2020$ by author(s) and Scientific Research Publishing Inc. This work is licensed under the Creative Commons Attribution International License (CC BY 4.0).

http://creativecommons.org/licenses/by/4.0/

\begin{abstract}
The provision of economic resources to countries at the shore of Gulf of Guinea is a very important effort that has helped West Africa to develop to some extent. Taking the study area as a system it will be important to know the dynamics that occur in it to help neighouring countries predict its physical and thermodynamics states at all times. Ghana is located in West Africa and it is bordered in the south by the Gulf of Guinea or Atlantic Ocean. The objective of this research is to characterize the hydrodynamic circulation of the Gulf of Guinea areas neighouring Ghana. A 3-Dimensional hydrodynamic model was implemented in the territorial waters of Ghana using the Modelo Hidrodinâmico, MOHID model to represent the dynamics and study the complex circulation pattern of the sea. To achieve this in an affordable computational time, nested domain approach was used to implement the hydrodynamic model in both 2 and 3-Dimensional gridded levels. The first level is a barotropic model with only tide. The nested domains of the rest of the levels are baroclinic forced with atmospheric and oceanic elements. To quantify its accuracy, the model was validated and calibrated in three stages; first, the frequency of the water level, followed by the circulation pattern and last, analysing the nature and profiles of the atmospheric and oceanic elements. The implemented model showed good agreement with the measured water surface level in the domain with mean error values not exceeding $14.00 \%$ of the measured data and with correlation factors higher than 0.80 . Also, the intensity and direction of velocity observed in the current data are well represented by the model at the water surface levels with mean errors lower than $20.00 \%$ of the measured data components. The profiles obtained for both the temperature and salinity at shore show completely a straight line for salinity and also a straight line which is slightly curved at the top for the temperature profile. The vertical straight line for the salinity profile shows that at the shore the waters are not stratified vertically or they are well mixed. The slight curve at the top of the temperature graph accounts for the mixing dy-
\end{abstract}


namics that occur close to land or the effect of heat flux at the surface. It can be concluded that the hydrodynamic model obtained by this study is the true reflection of the territorial waters of Ghana.

\section{Keywords}

Gulf of Guinea, Oceanic Circulation, Hydrodynamic, MOHID, Ghana

\section{Introduction}

The provision of economic resources to countries at the shore of Gulf of Guinea makes it very important to countries in West Africa [1]. Taking it as a system it will be important to know the dynamics (sea surface temperature, changes in density, current pattern, stratification of the sea, etc.) that occur in it to help neighouring countries predict its state at all times [2] [3] [4]. The use of numerical tools has made this possible. Numerical tools have the ability to help stakeholders link cause to effect, estimate and predict changes; and also as a tool to manage environmental phenomena with the best approach i.e. phytoplankton growth, water quality disturbance, etc. [5] [6] [7]. Oceanic circulation is caused by two processes namely, wind-driven or density-driven circulation and/or both and this is the key cause of bio-physical processes taking place in the Gulf of Guinea. Oceanic circulation influences all the activities in the oceanic ecosystem, including sediment transport, turbidity pattern, particle dispersal, etc. One other notable aspect of the environment ecosystem is the distribution, health and economic impact of bio-chemical particles (e.g. pollutant) in the marine world [5] [8] [9]. Circulation current patterns are of considerable interest to the Gulf of Guinea indigenous community who depend on the natural resources for their livelihood, as well as to industries that operate the region such as fisheries and shipping [1].

Ghana is located in West Africa. It is bordered with Ivory Coast at the west, north by Burkina Faso, east by Togo, and south by the Gulf of Guinea or Atlantic Ocean. It is located between longitude $3.25^{\circ} \mathrm{W}$ to $1.19^{\circ} \mathrm{E}$ and latitude $4.74^{\circ} \mathrm{N}$ to $11.18^{\circ} \mathrm{N}$. Accra is the capital city of Ghana situated in the Greater Accra Region and it stretches along the coast. Apart from Accra, there are other major cities like Takoradi, Sekondi, Cape Coast, Elmina, Keta, Tema, etc. also along the coast and the main occupation of the inhabitants is fishing. The coast is also filled with natural, sensitive and strategic resources like forts, castles, industries, water bodies (i.e. Volta river estuary and lagoon) and tourist sites. The discovery of commercial quantities of oil has placed all these resources under threat. The economic importance of the coast including ports and ports activities, high traffic of vessel activities, exploration exercises, local industries, fisheries and tourism justify the need for studying the hydrodynamics of the area [1] [10].

The objective of this research is to study the hydrodynamic circulation of the Gulf of Guinea areas neighouring Ghana. Another goal is to validate the MOHID 
water system model using data available to proof it capability to hydrodynamic modeling.

\section{Methodology}

In this research, Modelo Hidrodinâmico, MOHID model, a 3-Dimensional water modeling system was used [2]. It is designed in such a way that the domain is divided into various medium; land, air and water. The architecture is such that communication is done between media by interface modules (i.e. InterfaceSedimentWater Module and InterfaceWaterAir Module). These interfacial modules handle the fluxes between two media, either air and water or water and sediment.

In order to simulate all possible dynamics in an affordable computer processing unit (CPU) time, nested domain approach was used to implement the hydrodynamic model in both 2 and 3-Dimensional gridded levels. It is made up of three domains; Domains 1, 2, and 3 are contained in levels 1, 2, and 3, respectively. The first level is a barotropic model with only tide. The nested domains of the rest of the levels are baroclinic.

At the open boundaries, the main domain was forced with tide from the FES (Finite Element Solution), 2012 tide model. The domains of the second and third of the second and third levels are subdomains of the first level domain. Open boundaries come in the sense of surface and lateral boundaries with cell volume not sided by land. At these levels $\left(2^{\text {nd }}\right.$ and $\left.3^{\text {rd }}\right)$, they are purely 3 -Dimensional in grid. The free surface was forced with atmospheric conditions; Pressure from the Atmospheric, Wind velocity, Solar radiation, Air temperature, Relative Humidity, downward Long Wave Radiation and Cloud cover. The atmospheric data was taken from The Global Forecast System (GFS) which is a weather model.

A database containing the following average daily distribution information parameters was forced at the open boundary or lateral boundary (i.e. Temperature, Salinity, Velocity, and Water level). The forcing was done for both domains in the second and third levels for the horizontal grids with a vertical resolution of 43 layers. Closed boundaries were taken to be land cell where computation will not be performed.

The results were analysed statistically to investigate the margin of deviation from measured data.

\subsection{Implementation}

This section introduces the equations and assumptions involved in the implementation of the hydrodynamic model of the coastal waters of Ghana.

Hydrodynamics; the model solves the 3-Dimensional Navier Stokes incompressible primitive equations. Hydrostatic equilibrium is accounted for and also Boussinesq and Reynolds approximations as;

$$
\frac{\partial}{\partial t} \int_{V} \boldsymbol{v}_{H} \mathrm{~d} V=A+B+C+D
$$


where

$$
\begin{gathered}
A=-\oint_{A} \boldsymbol{v}_{H}(\boldsymbol{v} \cdot \boldsymbol{n}) \mathrm{d} A \\
B=\oint_{A} \boldsymbol{v}_{H}(\boldsymbol{v} \cdot \boldsymbol{n}) \mathrm{d} A \\
C=-\frac{1}{\rho} \oint_{A} p \cdot \boldsymbol{n}_{H} \mathrm{~d} A \\
D=\oint_{\boldsymbol{V}} 2 \boldsymbol{\Omega} * \boldsymbol{v}_{H} \mathrm{~d} V+\boldsymbol{F}
\end{gathered}
$$

The model is made to allow all these assumed approximations in its solution.

Considering momentum balance equations, a Cartesian scale for horizontal velocities is given as:

$$
\begin{aligned}
\partial_{t} u= & -\partial_{y}(u v)-\partial_{z}(u w)-\partial_{x}(u u)+f v-1 / \rho_{o}\left(\partial_{x} P\right) \\
& +\left(\partial_{x}\left(v_{H}+v\right) \partial_{x} u\right)+\left(\partial_{y}\left(v_{H}+v\right) \partial_{y} u\right)+\left(\partial_{z}\left(v_{t}+v\right) \partial_{z} u\right) \\
\partial_{t} v= & -\partial_{y}(v v)-\partial_{z}(u w)-\partial_{x}(v u)-f u-1 / \rho_{o}\left(\partial_{y} P\right) \\
& +\left(\partial_{x}\left(v+v_{H}\right) \partial_{x} v\right)+\left(\partial_{y}\left(v+v_{H}\right) \partial_{y} v\right)+\left(\partial_{z}\left(v_{t}+v\right) \partial_{z} v\right)
\end{aligned}
$$

where, $u, v$ and $w$ are the velocity vector components in the Cartesian coordinate that is the $x, y$ and $z$ directions respectively, $f$ the Coriolis parameter, $v_{H}$ and $v_{t}$ the viscosities for turbulent in the various directions that is horizontal and vertical directions, pressure is designated by $p$. The first three terms on the right stand for the changing velocities that is advective transport, the fourth term is Coriolis force, and the three terms following are the pressure gradient and turbulent diffusion (last three terms).

The mass balance equation (that is, the incompressible continuity equation) was used to compute the vertical velocity, $w$ by integrating the depth, $z$ and bottom, $-h$;

$$
\partial_{x} u+\partial_{y} v+\partial_{z} w=0
$$

The Reynolds and Boussinesq approximations were assumed in the model. Also, Hydrostatic equilibrium was assumed.

By using this expression and the Boussinesq approximation, the horizontal pressure gradient in the direction $X_{i}$ can be divided into three contributions;

$$
\partial_{x_{i}} P=\partial_{x_{i}} P_{a t m}-g \rho_{0} \partial_{x_{i}} \eta-g \int_{z} \eta \partial_{x_{i}} \rho \mathrm{d} z
$$

The density is estimated from the transported salinity and temperature within the domain by the water properties module. This estimation is done from the equation of state [7] by considering salinity and temperature;

$$
\begin{aligned}
\rho= & \left(5890-0.375 T^{2}+38 T+3 S\right) /\left(\left(1779.5-0.00745 T^{2}+11.25 T\right)\right. \\
& \left.-(3.8+0.01 T) S^{2}+0.698\left(5890-0.375 T^{2}+38 T+3 S\right)\right)
\end{aligned}
$$

Discretization; the Module for Geometry computes the boundary areas as well as the volume of the domain considering the bathymetry data and the free surface elevation. The model uses a finite volume approach [1] [8] [11] [12] to 
algebraically represent and solve the equations. The algebraic representation of the equation is applied to a cell control volume.

In the model, volume of an element is represented in a way that allows a degree of freedom in the vertical direction and in the horizontal grid, a Cartesian orthogonal is allowed which is staggered in an Arakawa C [3] manner. Arakawa $\mathrm{C}$ arrangement allows velocities to be located at the center of the cell under consideration; horizontal velocities are located in the center of the west (u-velocity) and south (v-velocities) faces, while elevation, turbulent magnitudes and tracers are placed in the center. Also, a staggering in the vertical direction is used, with vertical velocity $w$, tracers and turbulent magnitudes vertically placed in the top and bottom faces and horizontal velocities and elevation in the center of the element (in vertical). The temporal discretization described in [13] using semi-implicit algorithm: Alternate Direction Implicit was used. In all simulations, the 6 equations algorithm discretization schemes by [14] are used.

The ADI scheme calculates the horizontal velocities alternatively both explicitly and implicitly; that calculates one component of the horizontal velocity explicitly while the other is calculated implicitly, making sure that the internal and external modes have the same time steps [11].

\subsection{Boundary Conditions}

The model has the features of allowing five different boundary conditions; free surface, moving boundary, lateral closed or opened boundary and bottom boundary.

Free surface; a zero vertical advective fluxes over the surface is assumed. A flux at the surface (i.e. $W$ as flux) is:

$$
\left.W_{\text {flux }}\right|_{\text {surface }}=0
$$

By means of the wind surface stress, $\tau_{w}$, the Diffusive flux of momentum is explicitly imposed:

$$
\partial_{\bar{v}_{H}} /\left.\partial z\right|_{\text {surface }}=\tau_{w}
$$

Wind stress is estimated from a quadratic friction law:

$$
\boldsymbol{\tau}_{w}=C_{D} \rho_{a} \boldsymbol{W}|\boldsymbol{W}|
$$

where drag coefficient, $C_{D}$, depends on the wind speed. $W$ and $\rho_{a}$ are the measurements at a height of $10.00 \mathrm{~m}$ over the free sea surface for wind speed and air density respectively.

Bottom boundary; the bottom advective fluxes are imposed as null and diffusive flux of momentum is estimated by means of a bottom stress that is calculated by a non-slip method with a quadratic law that depends on the near-bottom velocity. So, the diffusive term at the bottom is written as:

$$
\left.v\left(\partial_{\bar{v}_{H}} / \partial z\right)\right|_{\text {bottom }}=C_{D} \boldsymbol{v}_{H}\left|\boldsymbol{v}_{H}\right|
$$

The drag coefficient, $C_{D}$, is estimated from the equation: 


$$
C_{D}=\left(K / \log \left(\left(z+z_{0}^{b}\right) / z_{0}^{b}\right)\right)^{2}
$$

where $\kappa$ and $z_{0}^{b}$ are the von Karman constant and the bottom roughness length respectively. The equation shows the characteristic of the law of the wall near boundaries especially at the bottom [15]. Also, at the bottom, a zero flux is assumed for both salinity and temperature.

Lateral closed boundaries; computation is limited by land. At this boundary the cells are impermeable. At the cell faces, surfacing land or in contact with land, a zero water and momentum diffusion fluxes are specified. During the implementation of this closed boundary a free slip condition is assumed;

$$
\begin{gathered}
\partial \bar{\nu}_{H} / \partial \eta=0 \\
\boldsymbol{v} \cdot \boldsymbol{n}=0
\end{gathered}
$$

Open boundaries; with the concept of nesting domains, localized areas like lagoons, lakes, estuaries, etc. can be studied. When a space within a region is extracted for a study, it should be implemented in such a way that guarantees values of the properties for both the region and the environment are allowed to enter and leave each other. The opening through which these properties are allowed between these two bodies or the surface/boundary through which they communicate is called open boundary [4] [7] [16].

Moving boundaries; when the position of the boundary changes with time it is referred to as moving boundary. Moving boundaries are closed boundaries in nature and change its position with time. They often exist at inter tidal zones where the points at the boundary are covered or uncovered by water with time within the domain. A stable algorithm is implemented within MOHID for these regions not to affect the hydrodynamics estimations, for example, at estuaries [12].

\section{Results and Discussion}

Figure 1 shows the levels considered during the hydrodynamic implementation to reduce computational time and memory allocation. The last level containing the $3^{\text {rd }}$ domain is the smallest with higher resolution compared to the first and second levels containing the $1^{\text {st }}$ and $2^{\text {nd }}$ domains respectively.

The minimum and maximum depths for the first domain are 10 and $433 \mathrm{~m}$ respectively, stretching from longitude $0.2^{\circ} \mathrm{N}$ to $6.0^{\circ} \mathrm{N}$ between latitude $4.95^{\circ} \mathrm{E}$ and $4.75^{\circ} \mathrm{W}$. It also has a 2-Dimensional geometry with one sigma vertical layer grid extending from the surface to the maximum depth of the bathymetry data (that is, $433 \mathrm{~km}$ ). Validation of simulated results was carried out at the following locations; Tema, Accra, Cape Coast and Takoradi at the third level. Figure 2 shows the locations of the tidal gauges for the four places.

Figure 3 shows graphs of water level obtained from the field and also from the hydrodynamic model and Figure 4, Figure 5 show temperature and salinity profiles of the same hydrodynamic model. 
The hydrodynamic pattern for the region is also shown in Figures 6(a)-(d) for particular time during the simulation period.

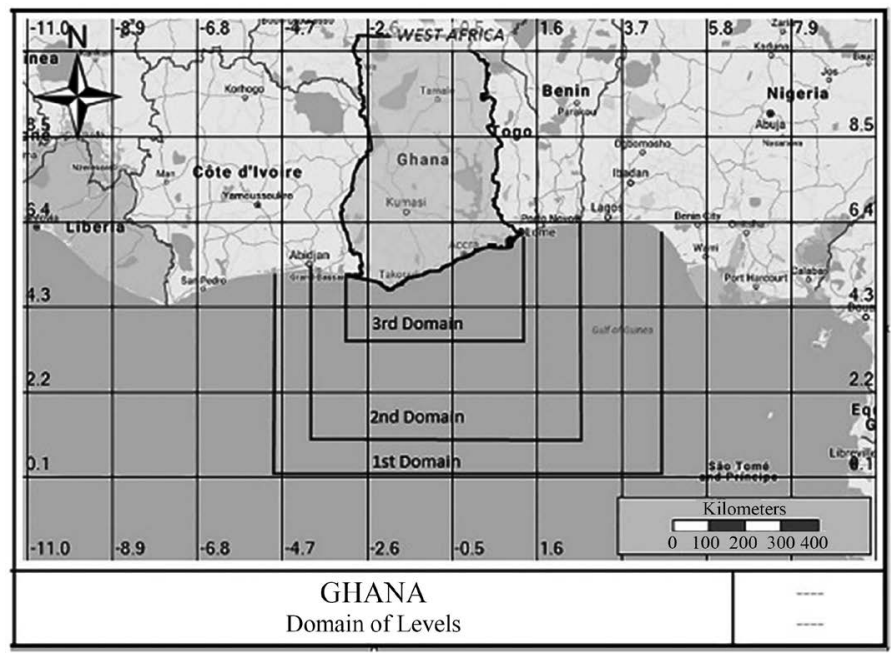

Figure 1. Resolutions of the various domain LEVELS.

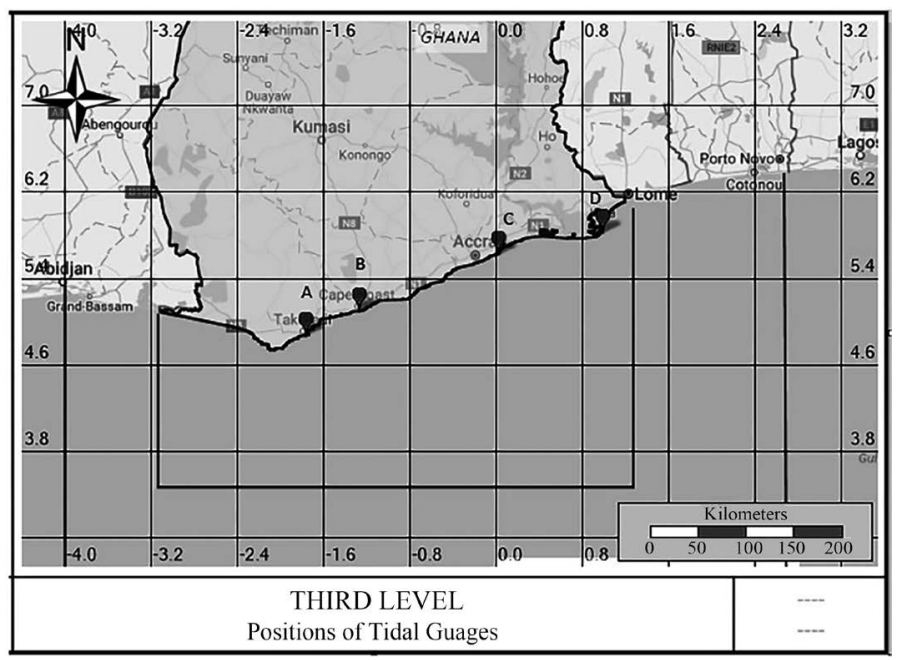

Figure 2. Tide Gauges location for validation.

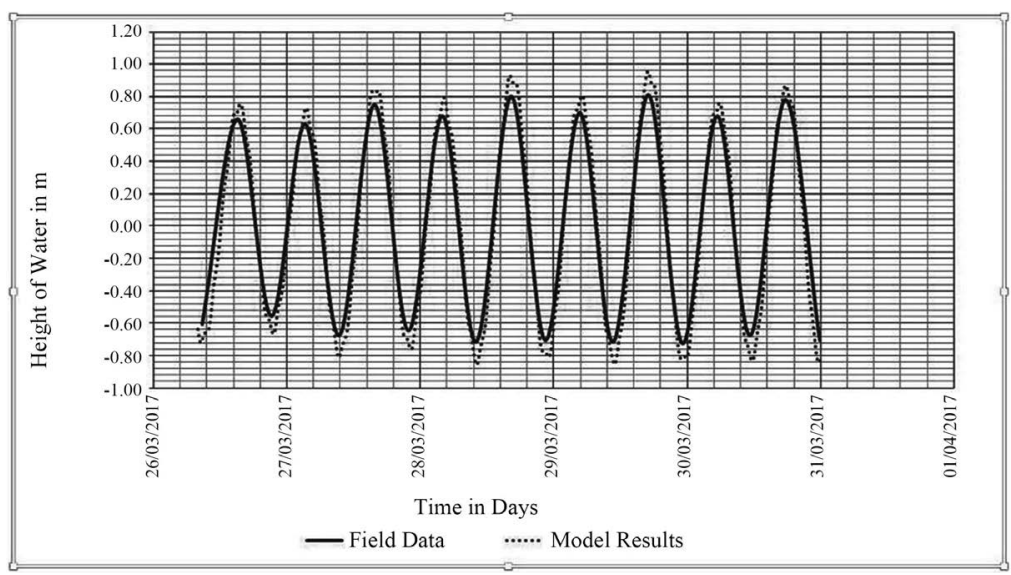

(a) 


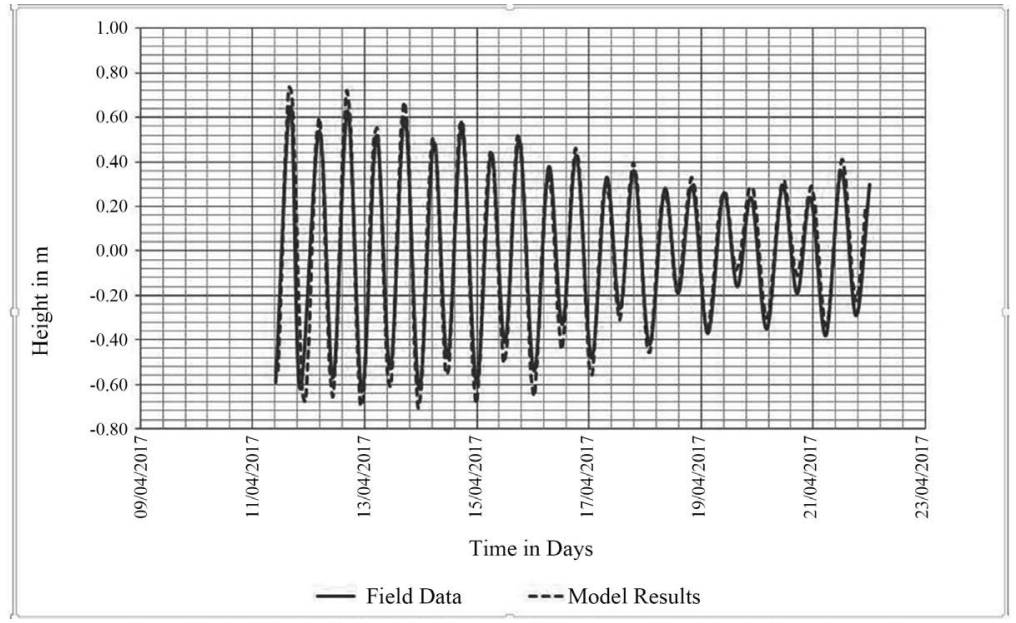

(b)

Figure 3. Validation of Hydrodynamic Model ((a) Takoradi Tide Gauge Series, and (b) Tema Tide Gauge Series).

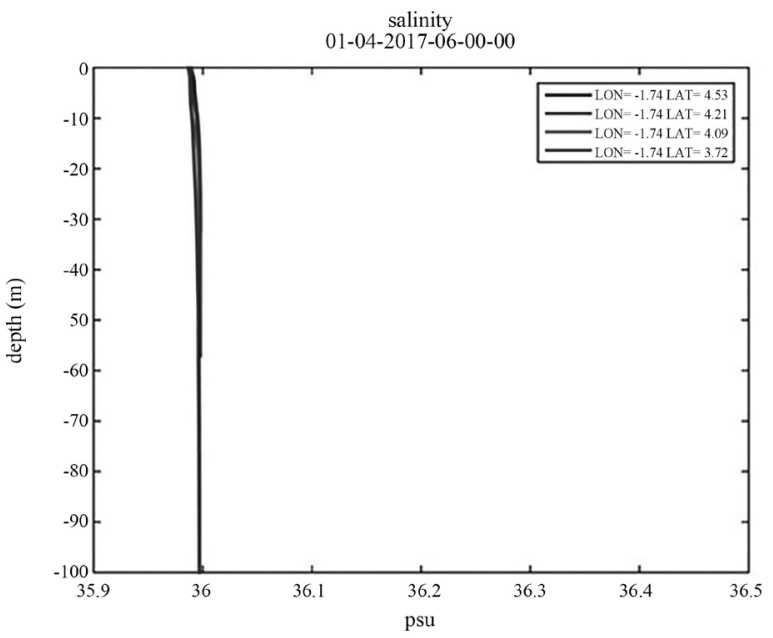

(a)

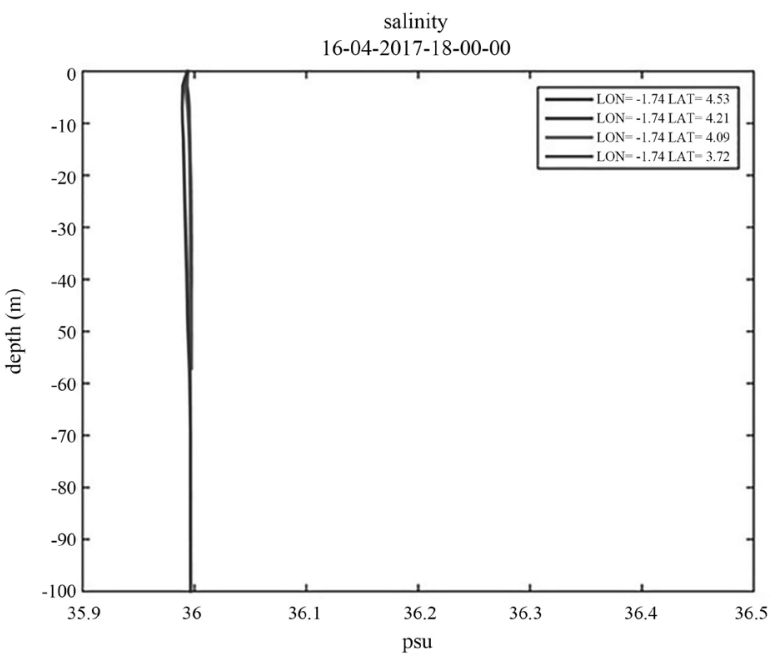

(b)

Figure 4. Salinity profiles for Hydrodynamic Model. 


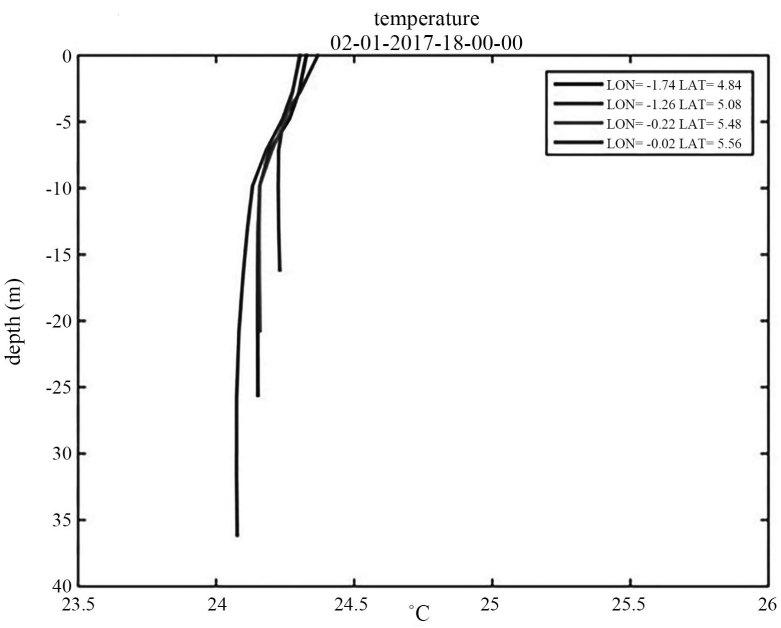

(a)

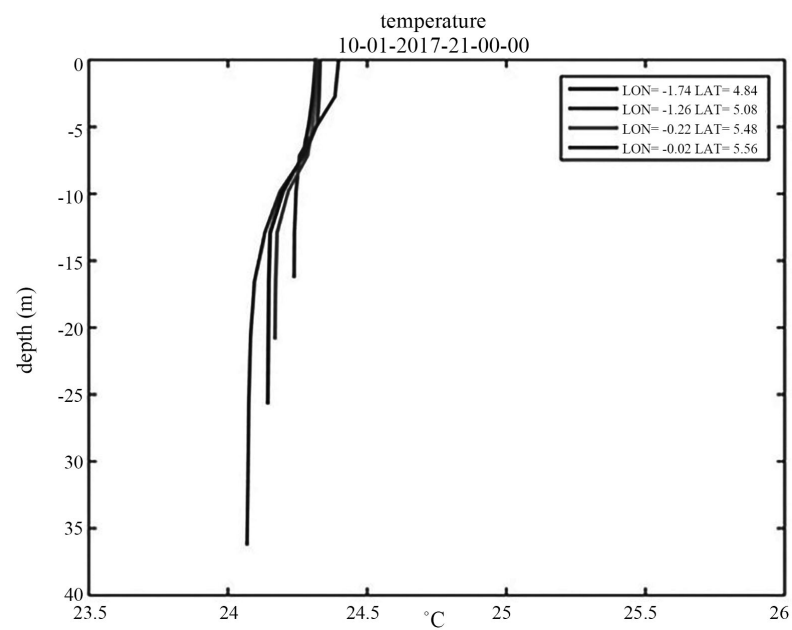

(b)

Figure 5. Temperature profiles for Hydrodynamic Model.

At each stage in the implementation, the model was validated. An overall validation was carried out at the end of the hydrodynamic model (i.e. the third level) looking at the water level, water currents and the pattern at the surface, salinity and temperature profiles.

From the graphs (Figures 3-6) the model simulations predicted very well and were very close to the measured data especially the tide frequency (Figure 3) at an accuracy margin of $14.00 \%$. The difference in tide measurements especially the simulated results deviating slightly from the measured data can be attributed to; the proximity of the installed gauges nearer to the shores. When tidal gauges are installed near the shore their readings are affected for example, by human activities around the tidal gauges; docking ships at the habour (which may agitate the sea water causing ripples) and obsolete measuring tools like dialed instrument can give some margin of errors. Also due to sedimentation from shoreline morphology or silt transportation some errors are introduced. Another contributing factor is the bathymetry resolution or poor bathymetry accuracy for lower areas. Hence, the differences in results. 


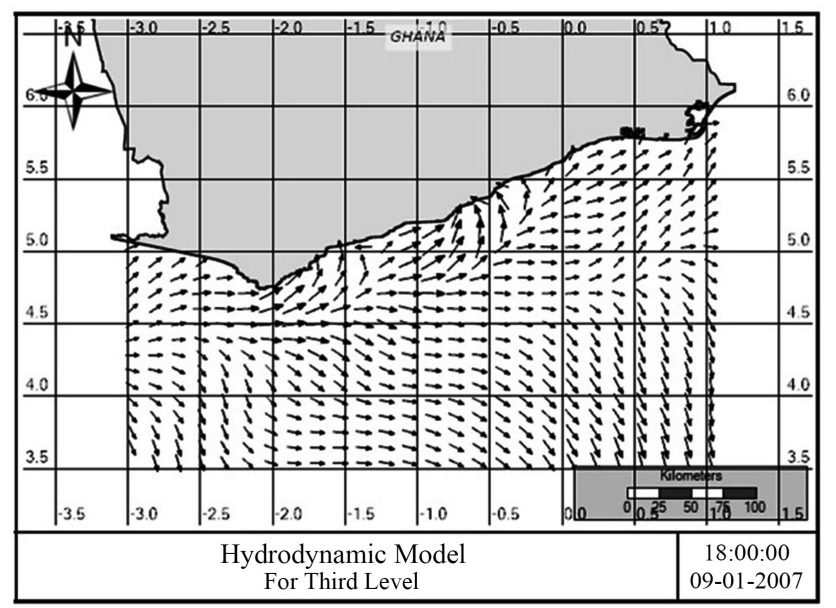

(a)

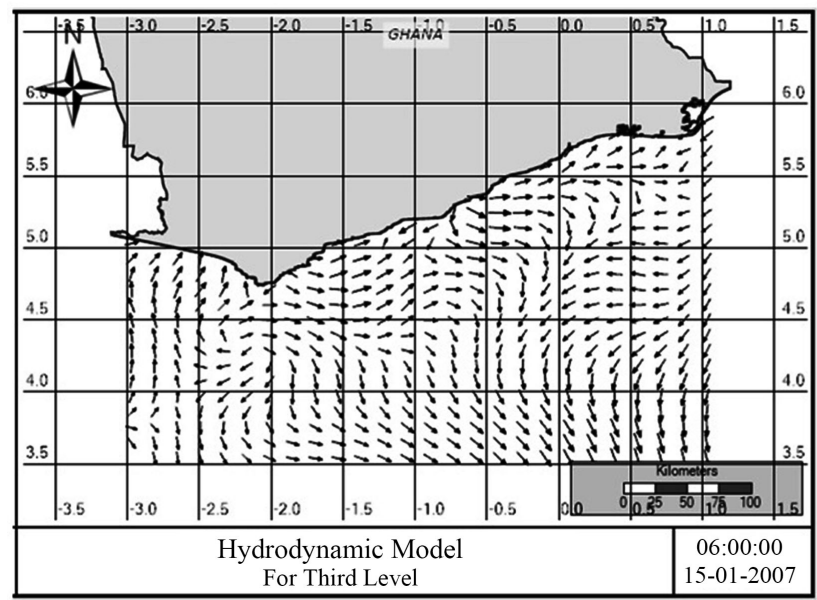

(c)

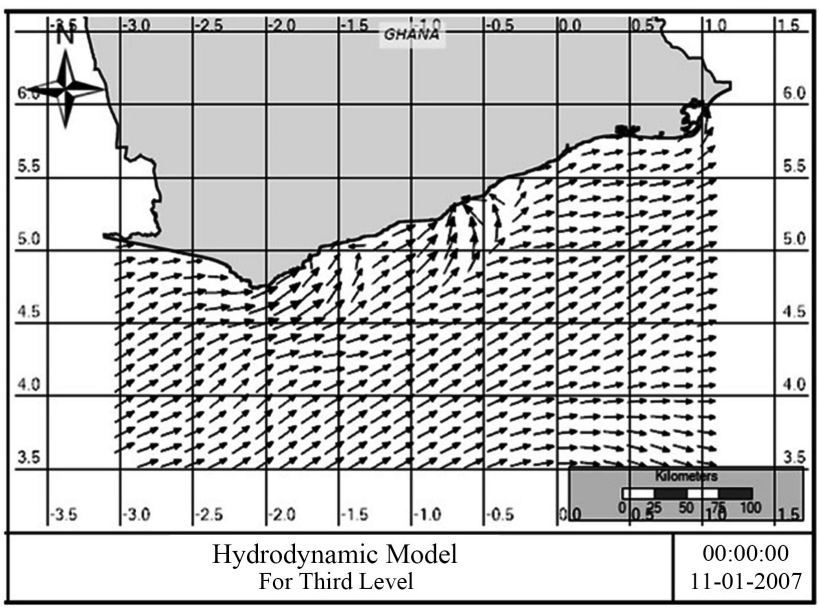

(b)

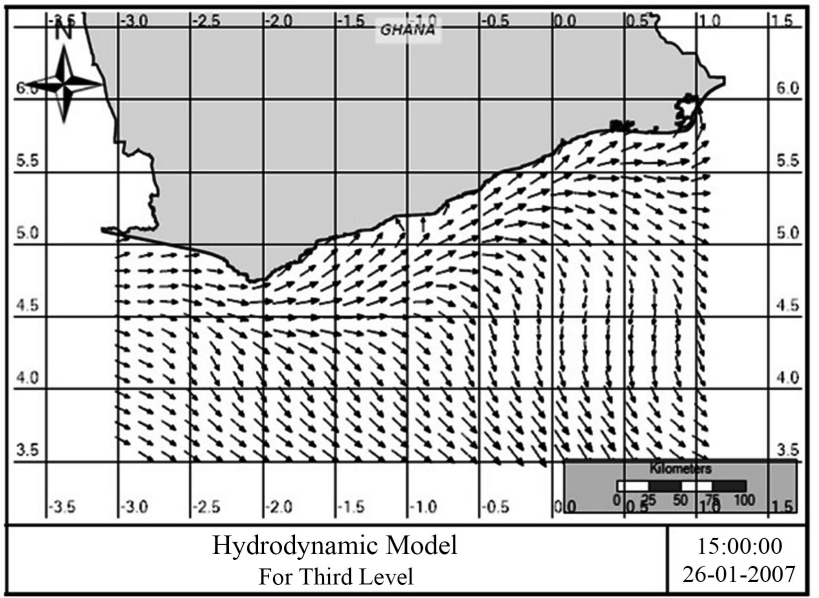

(d)

Figure 6. Hydrodynamic pattern for sellected dates.

The water current was also found to correlate with the measured data at a factor of $20.00 \%$. The pattern was in the same sense as the measured.

The temperature and salinity were analysed looking at their nature as the country lack weather station that keep such ocean elements. During the simulation also there was no algo float located within the domain. Both the temperature and salinity showed similar graph (i.e. almost straight line). The kind of line that was obtained by the salinity can be explained by the fact that the waters at the shore are well mixed. A slight difference was observed for the temperature at the top of the curve (i.e. slight curving at the top). The slight curve can be attributed to the fact that there is a mixing of hot fresh water from land or by the presence of heat flux at the surface of the water.

\section{Conclusions}

The 3-Dimensional Hydrodynamic model was used to simulate the dynamics of the Gulf of Guinea areas bordering Ghana. The model results were compared with measure data. The model results shown similar trend for most of the quan- 
tity validated (i.e. water circulation pattern; water levels; and profile for temperature and salinity). Maximum deviations of $14.00 \%$ and $20.00 \%$ for water level and water velocity respectively make them appropriate to be used for hydrodynamic forecasting in the coastal waters of Ghana.

The text edit has been completed, the paper is ready for the template. Duplicate the template file by using the Save As command, and use the naming convention prescribed by your journal for the name of your paper. In this newly created file, highlight all of the contents and import your prepared text file. You are now ready to style your paper.

\section{Acknowledgements}

The authors of the paper gratefully acknowledge the contribution of MARETEC, of Instituto Superior Tecnico, Universidade de Lisboa, Portugal for providing the research team with the required measuring equipment and support. The authors also wish to thank Prof. Ramiro Neves and Dr. Ligia Pinto from the same institution.

\section{Conflicts of Interest}

The authors declare no conflicts of interest regarding the publication of this paper.

\section{References}

[1] Amorin, R. and Broni-Bediako, E. (2013) Major Challenges in Ghana's Oil and Gas Discovery: Is Ghana Ready? ARPN Journal of Science and Technology, 3, 21-25.

[2] Fossati, M. and Piedra-Cueva, I. (2013) A 3D Hydrodynamic Numerical Model of the Río de la Plata and Montevideo's Coastal Zone. Applied Mathematical Modelling, 37, 1310-1332. https://doi.org/10.1016/j.apm.2012.04.010

[3] Arakawa, A. and Lamb, V.R. (1977) Computational Design of the Basic Dynamical Processes of the UCLA General Circulation Model. Methods of Computational Physics, 17, 174-264. https://doi.org/10.1016/B978-0-12-460817-7.50009-4

[4] Backhaus, J. (1985) A Three Dimensional Model for the Simulation of Shelf Sea Dynamics. Deutsche Hydrographische Zeitschrift, 38, 165-187. https://doi.org/10.1007/BF02328975

[5] Martins, F., Leitão, P., Silva, A. and Neves, R. (2000) 3D Modelling in the Sado Estuary Using a New Generic Vertical Discretization Approach. Oceanologica Acta, 24, S51-S62. https://doi.org/10.1016/S0399-1784(01)00092-5

[6] Santos, A.J. (1995) Modelo Hidrodinâmico Tridimensional de Circulação Oceânica e Estuarina. Ph.D. Thesis, Universidade Técnica de Lisboa, Instituto Superior Técnico.

[7] Palma, E. and Matano, R.P. (1998) On the Implementation of Passive Open Boundary Conditions for a General Circulation Model: The Barotropic Mode. Journal of Geophysical Research, 103, 1319-1342. https://doi.org/10.1029/97JC02721

[8] Leendertsee, J.J. and Liu, S.K. (1978) A Three-Dimensional Turdulent Energy Model for Non-Homogeneous Estuaries and Coastal Sea Systems. In: Nihoul, J.C.J., Ed., Hydrodynamics of Estuaries and Fjords, Elsevier Publ. Co., Amsterdam, 387-405. https://doi.org/10.1016/S0422-9894(08)71289-3

[9] Mateus, M. (2006) A Process-Oriented Biogeochemical Model for Marine Ecosys- 
tems: Development, Numerical Study and Application. Ph.D. Thesis, Technical University of Lisbon, Portugal.

[10] Zhou, C., Dongb, P. and Li, G. (2015) Hydrodynamic Processes and Their Impacts on the Mud Deposit in the Southern Yellow Sea. Marine Geology, 36, 1-16. https://doi.org/10.1016/j.margeo.2014.11.012

[11] Leitão, P.C. (2003) Integração de Escalas e de Processos na Modelação do Ambiente Marinho. Ph.D. Thesis, Instituto Superior Técnico, Universidade Técnica de Lisboa, Lisboa, Portugal, 296 p.

[12] Martins, F. (1999) Modelação Matemática Tridimensional de Escoamentos Costeiros e Estuarinos usando uma Abordagem de Coordenada Vertical Genérica. Ph.D. Thesis, Universidade Técnica de Lisboa, Instituto Superior Tecnico, Lisbon.

[13] Abbot, M.B. and Basco, D.R. (1994) Computational Fluid Dynamics: An Introduction for Engineers. Longman Scientific and Technical, London, 425 p.

[14] Leitão, P. (2003) Integração de Escalas e de Processos na Modelação no Ambiente Marinho. Ph.D. Thesis, Instituto Superior Técnico, Universidade Técnica de Lisboa, Lisbon, Portugal.

[15] Montero, P. (1999) Estudio de la hidrodinámica de la Ría de Vigo mediante un modelo de volúmenes finitos (Study of the Hydrodynamics of the Ría de Vigo by Means of a Finite Volume Model). Ph.D. Dissertation, Universidad de Santiago de Compostela, Spanish.

[16] Martinsen, E.A. and Engedahl, H. (1987) Implementation and Testing of a Lateral Boundary Scheme as an Open Boundary Condition in a Barotropic Ocean Model. Coastal Engineering, 11, 603-627. https://doi.org/10.1016/0378-3839(87)90028-7 